\title{
New Insights into the Molecular Mechanisms Targeting Tubular Channels/Transporters in PKD Development
}

\author{
Ming $\mathrm{Wu}$ Shengqiang Yu \\ Kidney Institute of PLA, Division of Nephrology, Shanghai Changzheng Hospital, Second Military Medical University, \\ Shanghai, PR China
}

\section{Key Words}

Polycystic kidney disease · Transporters · Channels .

Molecular mechanism

\begin{abstract}
Background: Autosomal dominant polycystic kidney disease (PKD) or autosomal recessive PKD is caused by a mutation in the PKD1, PKD2 or PKHD1 gene, which encodes polycystin-1, polycystin-2 or fibrocystin, respectively. Embryonic and postnatal mutation studies show that transport or channel function is dysregulated before the initiation of cystogenesis, suggesting that the abnormality of transport or channel function plays a critical role in the pathology of PKD. Summary: Polycystin-2 by itself is a calcium-permeable cation channel, and its channel function can be regulated by polycystin-1 or fibrocystin. In this paper, we reviewed the current knowledge about calcium transports and cyclic adenosine monophosphate (cAMP)-driven chloride transports in PKD. In addition, the function and the underlining mechanism of glucose transporters, phosphate transporters and water channels in PKD are also discussed. Key Messages: Abnormalities in calcium handling and exuberant CAMPdependent cystic fibrosis transmembrane conductance regulator-mediated fluid secretion in the collecting duct are the most important issues in the pathogenesis of PKD.
\end{abstract}

(C) 2016 S. Karger AG, Basel

\section{Introduction}

Polycystic kidney disease (PKD) is one of the most common hereditary kidney diseases in the world $[1,2]$. The incidence of autosomal dominant PKD (ADPKD) is 1 in $500-1,000$, whereas the autosomal recessive PKD (ARPKD) only affects 1 in 20,000 individuals [1]. ADPKD is caused by mutations in either the PKD1 or the PKD2 gene, which encodes polycystin-1 or polycystin-2, respectively. In ARPKD, mutations in PKHD1 lead to dysfunction of fibrocystin and subsequently form renal cysts [2].

Exuberant fluid secretion and cell proliferation drive the expansion of innumerous fluid-filled cysts in both kidneys of PKD patients $[1,2]$. In ADPKD, renal cysts develop in all segments of the nephron but predominantly originate from the collecting duct [3]. Renal cysts detach from their parental tubule when their diameter reaches $2 \mathrm{~mm}$ [4]. In ARPKD, the fusiform dilated collecting ducts form cysts and will not be disconnected from their parental tubules. The pathophysiology of PKD is not completely understood, and currently there is no approved pharmaceutical drug in the USA or China to treat $\mathrm{PKD}$ patients.

Inactivation of the $P k d 1$ gene before postnatal day 13 (P13) resulted in severe cystic kidneys within 3 weeks; however, $P k d 1$ gene inactivation after P13 did not induce

\section{KARGER}

E-Mail karger@karger.com

www.karger.com/kdd
C 2016 S. Karger AG, Basel

$2296-9381 / 16 / 0023-0128 \$ 39.50 / 0$
Prof. Shengqiang $\mathrm{Yu}$

Kidney Institute of PLA, Division of Nephrology

Shanghai Changzheng Hospital, Second Military Medical University

415 Fengyang Road, Shanghai 200003 (PR China)

E-Mail ysqdd1@126.com 
Table 1. Summary of channels and transports related to PKD

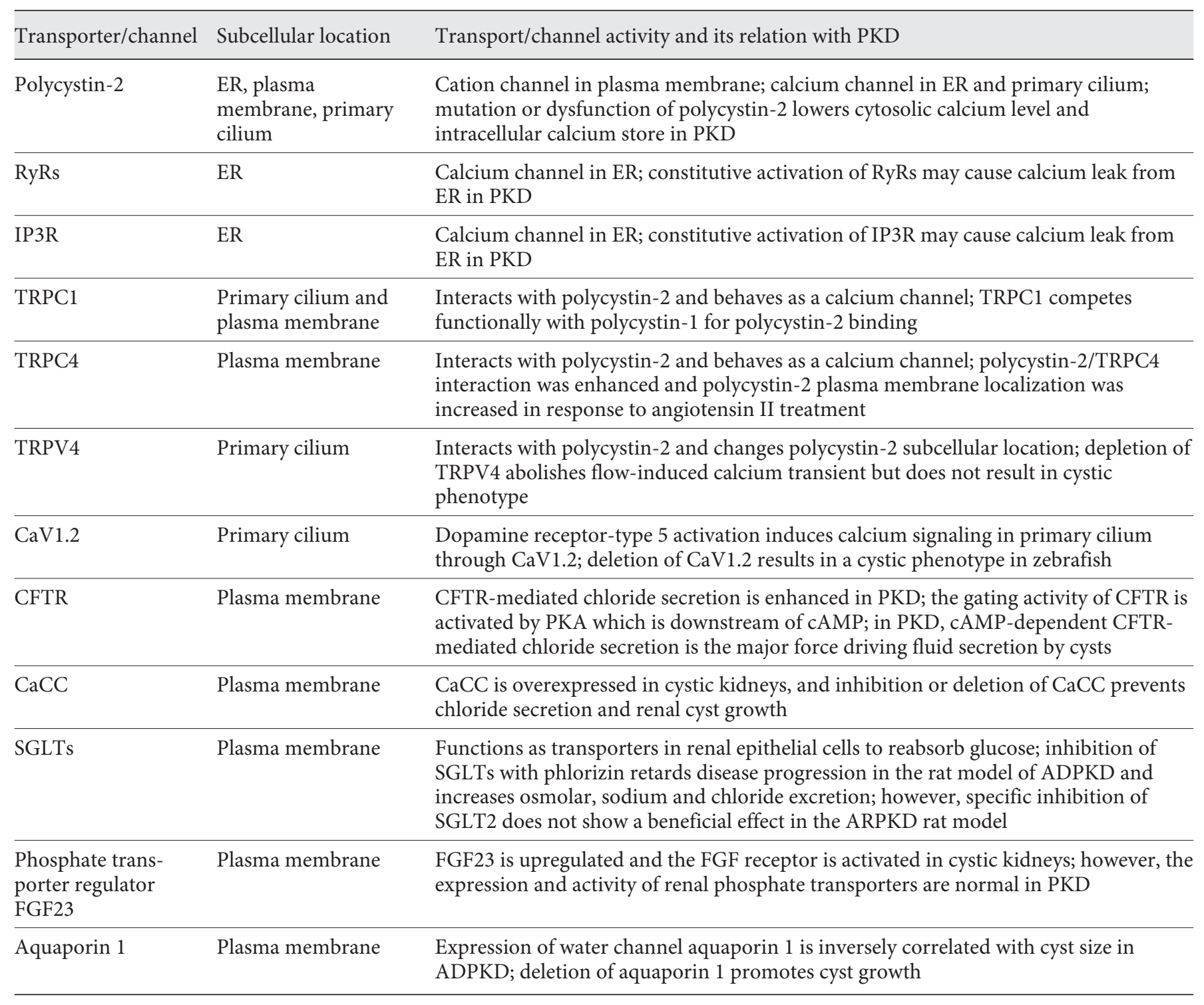

renal cyst within 3 months [5]. Microarray analysis revealed that differentially expressed genes between P11 and P12 are categorized into transporters or catalytic enzymes as compared with genes expressed between P14 and P15. Through amniotic fluid analysis, a massive loss of solutes and glucose was found in Pkd1-null embryos at E13.5 preceding cystogenesis [6]. These data suggest that tubular channels or transporters may play an important role in cystogenesis or development $[5,6]$. Channels or transporters which are related to PKD are summarized in table 1.

Mechanisms Targeting Tubular Channels/ Transporters in PKD

\section{Calcium Transporters in PKD}

Intracellular calcium homeostasis is disrupted in ADPKD, as demonstrated by reduced cytosolic calcium content, intracellular calcium store and dysregulated intracellular calcium channel activities [7, 8]. Dysregulated calcium homeostasis was also observed in $\operatorname{ARPKD}[9,10]$. A lower intracellular calcium level was found in ARPKD cells or PKHD1-silenced cells. Polycystin-2 is a calciumpermeable cation channel, and its channel selectivity is determined by its subcellular localization [11]. On plasma 
membrane, polycystin- 2 is a receptor-operated nonselective cation channel, while it functions as a calcium channel when localized to the primary cilium or endoplasmic reticulum (ER) [11]. In general, the transmembrane protein polycystin-1 and polycystin-2 form a complex that functions as a mechanic sensor when it is localized in the primary cilium [1]. In normal physiological condition, polycystin-1 transduces extracellular mechanic signals by enhancing calcium influx through the calcium channel polycystin-2 in the primary cilium. In ADPKD, the dysfunction of polycystin-1 or polycystin-2 reduces intracellular calcium level and results in cystogenesis.

The channel activity of polycystin-2 can be activated by intracellular calcium, epidermal growth factor or binding to polycystin-1 [11]. Recently, it has been shown that phosphorylation of polycystin-2 at Ser829 increased adenosine $5^{\prime}$-triphosphate (ATP)-induced calcium transients [12]. The function of polycystin-2 can also be modulated through changing its subcellular localization [11, 13]. It has been shown that the phosphorylation status of polycystin-2 determines its subcellular distribution [11]. Phosphorylation of polycystin- 2 on serine 812 by casein kinase 2 traps it in the ER [14]. Constitutive phosphorylation of polycystin- 2 on serine 76 by glycogen synthase kinase 3 leads to plasma membrane localization of polycystin-2 [15]. The study by Streets et al. [12] firstly showed that polycystin-1 is also engaged in polycystin-2 phosphorylation. Dysfunction of polycystin-1 increased polycystin-2 phosphorylation at Ser829 through activating the cyclic adenosine monophosphate (cAMP)/protein kinase A (PKA) pathway or releasing PP1-mediated dephosphorylation on Ser829 by disrupting polycystin-1 and polycystin-2 interaction [12]. Following cAMP stimulation, basolateral expression of pSer829 increased to a greater extent than its ER expression [12].

Mutation of the PKHD1 gene results in the dysfunction of fibrocystin/polyductin, a large transmembrane receptor-like protein [16]. Fibrocystin physically interacts with the intracellular $\mathrm{N}$-terminal tail of polycystin-2 through its intracellular C-terminus [17]. The binding of fibrocystin and polycystin-2 requires the presence of ciliary motor protein kinesin-2 [18]. Several lines of evidence revealed that downregulation of fibrocystin reduces intracellular calcium level. Fibrocystin regulates intracellular calcium homeostasis probably through modulating the channel activity of polycystin-2 and preventing degradation of polycystin-2 $[10,18,19]$. Overexpression of fibrocystin C-terminus activated polycystin-2 channel activity and also prevented its downregulation $[17,18]$.

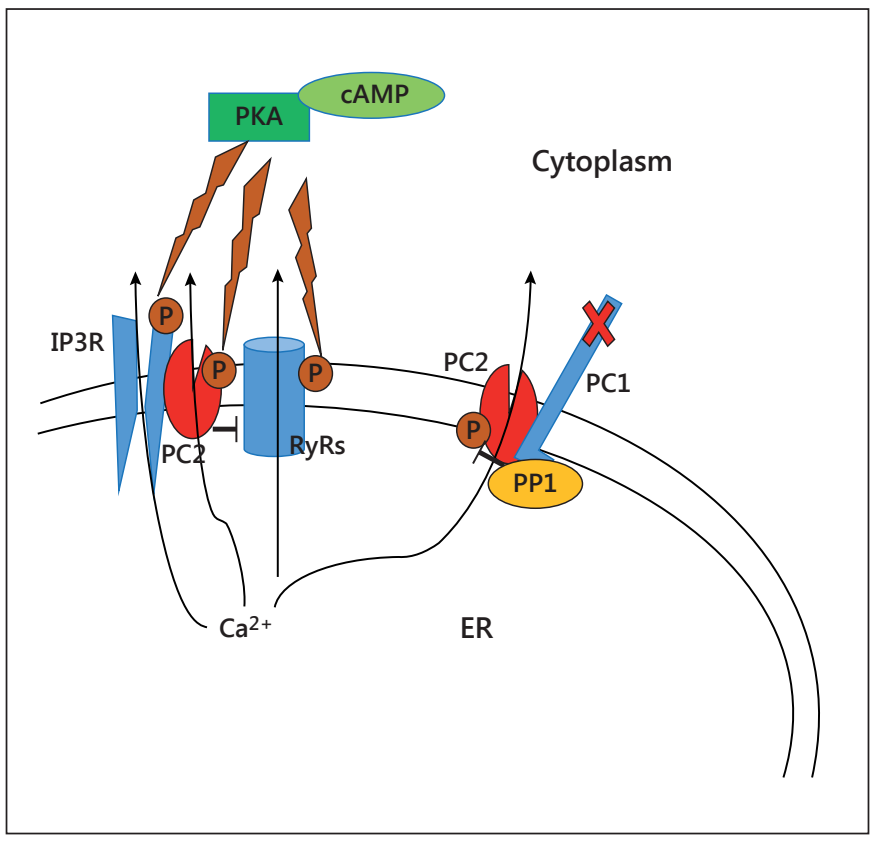

Fig. 1. Putative mechanism of calcium leak from ER in PKD. In $\mathrm{PKD}$, a high level of intracellular cAMP activates PKA which in turn phosphorylates and enhances the gating activity of polycystin-2 (PC2), RyRs and IP3R in the ER. Constitutive activation of PC2, RyRs and IP3R results in calcium leak and depletion of the intracellular calcium store in PKD. Moreover, PC2 behaves as a brake to inhibit RyR activity, and dysfunction of PC2 may also cause calcium leak through RyRs. Polycystin-1 (PC1) inhibits PC2 activity through PP1-mediated dephosphorylation of PC2. PP1 interacts with PC1, and dysfunction of PC1 releases PP1-mediated PC2 dephosphorylation, thus promoting calcium leak through PC2.

In addition to acting as a calcium channel by itself, polycystin-2 modulates intracellular calcium homeostasis by physically interacting and regulating multiple calcium channels $[7,20]$. Polycystin-2 colocalizes with ryanodine receptors (RyRs) in ER and inhibits its calcium release as a brake $[8,21,22]$. Knockout of $P K D 2$ results in depletion of intracellular calcium store and alteration of RyRs-dependent calcium signaling [21]. There is another mechanism that may account for the reduced internal calcium store in ADPKD. It is postulated that constitutive activation of polycystin-2 and RyRs by a high level of cAMP/PKA results in calcium leak and depletion of intracellular calcium store in PKD1- or PKD2-mutated renal epithelial cells (fig. 1) [20]. Moreover, polycystin-2 also interacts and activates calcium release through inositol 1,4,5-trisphosphate receptor (IP3R) in ER [23]. Mutation or downregulation of polcystin-2 decreases IP3evoked calcium response $[8,23]$. In addition, IP3R could 
be phosphorylated and functionally regulated by PKA $[24,25]$. Therefore, we cannot exclude that a constitutive activation of IP3R by PKA in PKD leads to calcium leak from the internal calcium store (fig. 1). A recent study shows that aging disrupts the functional interaction between polycystin-2 and RyRs or IP3, which might contribute to the accelerated disease progression in elderly ADPKD patients [8]. The putative molecular mechanism for the observed aging-related calcium handling abnormality could be related to the phosphorylation status of polycystin-2 and/or its binding partners [8].

Polycystin-2 belongs to the transient receptor potential (TRP) family of ion channels and is named as TRPP2 $[11,26]$. Several studies showed that polycystin-2 complexes and other TRP family members such as TRPC1, TRPC4 and TRPV4 function as molecular sensors by regulating calcium influx [26-29]. Interestingly, deletion of TRPV4 did not result in the cystic phenotype in kidneys, although TRPV4 depletion completely abolished flowinduced calcium signaling [29]. These studies also found that TRP channels can regulate polycystin-2 subcellular distribution and compete with polycystin-1 for polycystin-2 binding; however, the impact of these channels on polycystin-1- or polycystin-2-mediated calcium signaling and intracellular calcium store in ADPKD is currently unknown.

Polycystin-1 may also participate in the regulation of intracellular calcium content, since it was found to physically interact with ER-localized calcium release channel IP3R [30]. However, experimental findings regarding the effect of polycystin-1 on IP3-evoked calcium release were inconsistent $[30,31]$. A recent study in a more restricted experimental condition with stable resting calcium level and no reuptake of calcium, showed that endogenous polycystin- 1 stimulated the activity of IP3R in the presence of polycystin-2 [32].

The L-type $\mathrm{Ca}^{2+}$ channel alpha $1 \mathrm{C}(\mathrm{CaV} 1.2)$ was found localized in the primary cilium of renal epithelial cells [33]. A recent study showed that zebrafish with CaV1.2 deletion presents a cystic phenotype [34]. Interestingly, CaV1.2 is upregulated in PKD-2 knockout cystic zebrafish and cilia-deficient cells. Further study needs to explain the effect of CaV1.2 overexpression in PKD.

\section{Chloride Transporters in PKD}

An early study with tritium showed that daily fluid turnover within a renal cyst is 10 times more than the cyst volume [35]. The transepithelial membrane fluid secre-

Mechanisms Targeting Tubular Channels/

Transporters in PKD tion across the polarized monolayer of several epithelial cell lines was observed, and the fluid secretion was stimulated by a cAMP agonist [36, 37]. Moreover, forskolin, a nonspecific stimulator of adenylate cyclase, enhanced fluid secretion by excised human renal cysts [37]. Cystic fibrosis transmembrane conductance regulator (CFTR)mediated chloride transport has been identified as the major force for CAMP-induced transmembrane fluid secretion in ADPKD $[38,39]$. Several in vitro and in vivo studies indicated that CFTR is required for cAMP-stimulated cyst formation and expansion [40-42]. It is well known that the gating activity of CFTR is regulated by cAMP-dependent phosphorylation on the CFTR regulatory domain through PKA [43]. Therefore, it is believed that fluid accumulation in renal cysts is caused by active chloride secretion through CFTR which is stimulated by the cAMP/PKA pathway.

The energy of active chloride excretion in $\mathrm{PKD}$ is powered by the basolateral sodium-potassium ATPase which generates a chemical gradient driving the entry of potassium and chloride through basolateral sodium, potassium and chloride $\left(\mathrm{Na}^{+}-\mathrm{K}^{+}-2 \mathrm{Cl}^{-}\right)$co-transporters [44, 45]. In $\mathrm{PKD}$, chloride is excreted to lumen following the chemical gradient through cAMP-stimulated CFTR and creates a lumen-negative transepithelial electrical potential [44]. Potassium moves back through basolateral potassium channels $[46,47]$. The lumen-negative potential generated by the chloride and potassium conductance drives sodium passively transported into lumen through a paracellular pathway [44]. The net increase in sodium and chloride in lumen leads water secretion by osmotic forces [44]. Inhibition $\mathrm{Na}^{+}, \mathrm{K}^{+}$-ATPase, and $\mathrm{Na}^{+}$- and $\mathrm{K}^{+}$$2 \mathrm{Cl}^{-}$co-transporters and potassium transporters in the basolateral membrane inhibits chloride secretion and cyst expansion [42, 45-47].

In parallel to the predominant presentation of cysts in the collecting duct in PKD, the inner medullary collecting duct, especially the initial part has a robust capacity to secrete chloride in response to cAMP treatment [48]. The $\mathrm{V} 2$ receptor of arginine vasopressin (AVP) is predominantly located in the collecting duct and also expressed in the medullary thick ascending limb [49]. AVP interacts with the V2 receptor on the basolateral membrane to promote cAMP production through adenylyl cyclase 6 which is abundantly expressed in the inner medulla, and subsequently stimulates CFTR-mediated chloride secretion in ADPKD cells [50-53]. Numerous studies in cells, animals and recently in human settings have proven that AVPstimulated cAMP production is a major factor for chloride-driven fluid secretion in PKD. Blocking the V2 re- 
ceptor with different antagonists or lowering the plasma level of AVP by increasing water intake reduced renal cAMP levels and delayed cyst growth in animal models of PKD and ADPKD [53-57].

AVP promotes chloride secretion also indirectly by producing ATP or prostaglandin $\mathrm{E}_{2}$ (PGE2) $[58,59]$. ATP was found accumulated in renal cysts in ADPKD patients [60]. It has recently been shown that ATP stimulation is required for the cAMP-dependent fluid secretion in the 3D cyst culture model; however, the current theory of ATP-stimulated chloride secretion involves increasing intracellular calcium concentration and activation of calcium-activated chloride channels (CaCC) [61-63]. CaCC is indeed strongly expressed in animal and human cystic kidneys, and inhibition or deletion of $\mathrm{CaCC}$ prevents chloride secretion and renal cyst growth [64]. However, the mechanism of ATP-driven chloride transport still needs to be further explored in cells with low intracellular calcium levels. PGE2 is accumulated in renal cysts and interacts with EP2 or EP4 receptors to promote chloride secretion and cyst expansion [65, 66]. A mechanistic study has shown that PGE2 induced chloride secretion by collecting duct cells involving cAMP-CFTR-and/or calcium-CaCC-dependent channel functions [25].

The function of CTFR in ADPKD is also regulated by other paracrine factors. A recent study has shown that endogenous concentrations of ouabain stimulate chloride secretion by ADPKD cells via epidermal growth factor [67]. The adrenergic system stimulates cAMP-dependent chloride secretion in the collecting duct through activation of the $\beta$-adrenergic receptor, which involves cAMP production by ADPKD cells $[68,69]$.

Besides PKA, CFTR is controlled by numerous kinases [64]. Adenosine monophosphate-activated protein kinase (AMPK) is a negative regulator for CFTR activity. Activation of AMPK by metformin inhibited CFTR-dependent fluid secretion and slowed cyst growth [70]. A recent study showed that Src and mitogen-activated protein kinase (MEK/MAPK) were involved in ouabainstimulated and CFTR-mediated chloride secretion in ADPKD cells [67].

\section{Sodium-Glucose Cotransporters in PKD}

The sodium-glucose linked transporters (SGLTs) expressed in the proximal tubule are responsible for glucose homeostasis which is regulated by the kidney [71]. Inhibition of SGLTs with phlorizin retarded PKD progression in the Han:SPRD rat model accompanied by increased osmolar, sodium and chloride excretion [72]. Phlorizin inhibited the growth of cysts which are predominantly expressed in the proximal tubule in this rat model by inhibition of cell proliferation which might be linked to the MAPK signaling pathway. In addition, the authors postulated that increased osmotic diuresis induced by phlorizin may impair the transepithelial fluid secretion and thus inhibit cyst expansion. However, a later study from the same group showed that inhibition of SGLT2 with dapagliflozin worsened renal function and increased cystic volume in a PCK rat model of ARPKD where cysts are predominantly presented in collecting ducts and are not closed off from their parental tubules [73]. They explained that the increased intratubular osmotic pressure induced dilation of distal tubular segments and cysts, since the cell proliferation and cAMP levels in cystic kidneys were not changed by SGLT2 inhibition. Therefore, ADPKD patients with diabetes should be cautious to use SGLT inhibitors to control hyperglycemia until the effect and underlying molecular mechanism of SGLTs inhibitors are confirmed in orthologous animal models of ADPKD.

\section{Phosphate Transporter Regulation by Fibroblast Growth Factor 23 in PKD}

Fibroblast growth factor 23 (FGF23) is a hormone regulating phosphate reabsorbance in proximal tubules by downregulation of sodium phosphate co-transporters [74]. In animal and human PKD, the plasma level of FGF23 is upregulated; however, the plasma level of phosphate is not reduced in animals and humans with ADPKD $[75,76]$. In addition, animal studies showed that the expression and activity of renal phosphate transporters and the FGF23 co-ligand klotho are also normal in $\mathrm{PKD}$ as compared with wild-type rats, indicating PKD is resistant to overexpression of FGF23. Interestingly, FGF23 is strongly stained on cystic epithelial cells, and the FGF receptor is activated in cystic kidneys, suggesting that FGF23 may have an effect on cyst growth [75].

\section{Aquaporin Water Channels in PKD}

Water channel aquaporin 1 and aquaporin 2 are expressed in renal cysts in ADPKD [77, 78]. The expression of aquaporin 1 is inversely correlated with cyst size; however, the expression of aquaporin 2 is not changed in small and large renal cysts [77]. Aquaporin 1 is located in the proximal tubules, the descending thin limbs of Hen- 
le's loop and the outer medullary descending vasa recta [79]. Overexpression of aquaporin 1 inhibited cell proliferation and impaired cystogenesis in a 3-D culture model [80]. Conversely, aquaporin 1 deletion promoted cyst growth, particularly in proximal tubule cysts, in animal models [80]. Aquaporin 1 interacts with $\beta$-catenin and promotes its degradation, and deletion of aquaporin 1 increases $\beta$-catenin expression and activates downstream Wnt signaling pathway leading to cystogenesis [80].

\section{Conclusions}

The deficient calcium handling, low levels of intracellular calcium and reduced calcium storage are fundamental defects in PKD. Current studies in the field of PKD focus on understanding the abnormal calcium signaling conducted by polycystin-2. Regulation of calcium storage by RyRs and IP3R in PKD is another hot research topic, since these two calcium channels can be tightly regulated by polycystin-1, polcystin-2 and cAMP. CFTR-dependent cAMP-driven fluid secretion is an important issue in this field. The concept of inhibition of cAMP-driven fluid secretion is encouraged by the positive result obtained from a clinical trial using the V2 receptor antago- nist tolvaptan in ADPKD patients. The activity of CFTR is regulated by an array of kinases, which could be designed as targets to treat $\mathrm{PKD}$ patients in the future. $\mathrm{CaCC}$ is also involved in fluid secretion in PKD; however, more studies need to be performed to understand its working mechanism in the low calcium environment in PKD. Many studies regarding the transporters or channels located in the proximal tubules in PKD are also encouraging. However, cysts in ADPKD and ARPKD are predominantly found in the collecting duct. More importantly, cysts located in the distal part of the nephron have more potential effects than the proximal tubule cysts to affect renal function [4].

\section{Acknowledgements}

This work was supported by National Natural Science Foundation of China General Projects (81370784) to S. Yu, and National Science \& Technology Pillar Program (ID: 2013BAI09B04).

\section{Conflict of Interest Statement}

The authors declare that there is no conflict of interest.

\section{References}

$\checkmark 1$ Paul BM, Vanden Heuvel GB: Kidney: polycystic kidney disease. Wiley Interdiscip Rev Dev Biol 2014;3:465-487.

2 Grantham JJ: Rationale for early treatment of polycystic kidney disease. Pediatr Nephrol 2015;30:1053-1062.

-3 Verani RR, Silva FG: Histogenesis of the renal cysts in adult (autosomal dominant) polycystic kidney disease: a histochemical study. Mod Pathol 1988;1:457-463.

-4 Grantham JJ, Mulamalla S, Swenson-Fields KI: Why kidneys fail in autosomal dominant polycystic kidney disease. Nat Rev Nephrol 2011;7:556-566.

5 Piontek K, Menezes LF, Garcia-Gonzalez MA, Huso DL, Germino GG: A critical developmental switch defines the kinetics of kidney cyst formation after loss of Pkd1. Nat Med 2007;13:1490-1495.

-6 Ahrabi AK, Jouret F, Marbaix E, Delporte C, Horie S, Mulroy S, et al: Glomerular and proximal tubule cysts as early manifestations of Pkd1 deletion. Nephrol Dial Transplant 2010; 25:1067-1078.

7 Torres VE, Harris PC: Strategies targeting cAMP signaling in the treatment of polycystic kidney disease. J Am Soc Nephrol 2014;25: 18-32.
8 Abdi A, Mazzocco C, Legeron FP, Yvert B, Macrez N, Morel JL: TRPP2 modulates ryanodine- and inositol-1,4,5-trisphosphate receptors-dependent $\mathrm{Ca}^{2+}$ signals in opposite ways in cerebral arteries. Cell Calcium 2015. 58:467-475.

-9 Yamaguchi T, Hempson SJ, Reif GA, Hedge AM, Wallace DP: Calcium restores a normal proliferation phenotype in human polycystic kidney disease epithelial cells. J Am Soc Nephrol 2006;17:178-187.

$\rightarrow 10$ Yang J, Zhang S, Zhou Q, Guo H, Zhang K, Zheng R, Xiao C: PKHD1 gene silencing may cause cell abnormal proliferation through modulation of intracellular calcium in autosomal recessive polycystic kidney disease. J Biochem Mol Biol 2007;40:467-474.

11 Tsiokas L, Kim S, Ong EC: Cell biology of polycystin-2. Cell Signal 2007;19:444-453.

12 Streets AJ, Wessely O, Peters DJ, Ong AC: Hyperphosphorylation of polycystin-2 at a critical residue in disease reveals an essential role for polycystin-1-regulated dephosphorylation. Hum Mol Genet 2013;22:1924-1939.

13 Fu X, Wang Y, Schetle N, Gao H, Putz M, von Gersdorff G, et al: The subcellular localization of TRPP2 modulates its function. J Am Soc Nephrol 2008;19:1342-1351.
14 Kottgen M, Benzing T, Simmen T, Tauber R, Buchholz B, Feliciangeli S, et al: Trafficking of TRPP2 by PACS proteins represents a novel mechanism of ion channel regulation. EMBO J 2005;24:705-716.

15 Streets AJ, Moon DJ, Kane ME, Obara T, Ong AC: Identification of an $\mathrm{N}$-terminal glycogen synthase kinase 3 phosphorylation site which regulates the functional localization of polycystin-2 in vivo and in vitro. Hum Mol Genet 2006;15:1465-1473.

-16 Ward CJ, Hogan MC, Rossetti S, Walker D, Sneddon T, Wang X, et al: The gene mutated in autosomal recessive polycystic kidney disease encodes a large, receptor-like protein. Nat Genet 2002;30:259-269.

17 Kim I, Li C, Liang D, Chen XZ, Coffy RJ, Ma $\mathrm{J}$, et al: Polycystin-2 expression is regulated by a PC2-binding domain in the intracellular portion of fibrocystin. J Biol Chem 2008;283: 31559-31566.

18 Wu Y, Dai XQ, Li Q, Chen CX, Mai W, Hussain $Z$, et al: Kinesin-2 mediates physical and functional interactions between polycystin-2 and fibrocystin. Hum Mol Genet 2006;15: 3280-3292. 
19 Kim I, Fu Y, Hui K, Moeckel G, Mai W, Li C, et al: Fibrocystin/polyductin modulates renal tubular formation by regulating polycystin- 2 expression and function. J Am Soc Nephrol 2008; 19:455-468.

20 Harris PC, Torres VE: Genetic mechanisms and signaling pathways in autosomal dominant polycystic kidney disease. J Clin Invest 2014;124:2315-2324.

-21 Anyatonwu GI, Estrada M, Tian X, Somlo S, Ehrlich BE: Regulation of ryanodine receptor-dependent calcium signaling by polycystin-2. Proc Natl Acad Sci USA 2007; 104: 6454-6459.

-22 Kuo IY, Kwaczala AT, Nguyen L, Russell KS, Campbell SG, Ehrlich BE: Decreased polycystin 2 expression alters calcium-contraction coupling and changes beta-adrenergic signaling pathways. Proc Natl Acad Sci USA 2014; 111:16604-16609.

-23 Li Y, Wright JM, Qian F, Germino GG, Guggino WB: Polycystin 2 interacts with type I inositol 1,4,5-trisphosphate receptor to modulate intracellular $\mathrm{Ca}^{2+}$ signaling. J Biol Chem 2005;280:41298-41306.

24 Soulsby MD, Wojcikiewicz RJ: The type III inositol 1,4,5-trisphosphate receptor is phosphorylated by cAMP-dependent protein kinase at three sites. Biochem J 2005;392:493497.

-25 Rajagopal M, Thomas SV, Kathpalia PP, Chen Y, Pao AC: Prostaglandin E2 induces chloride secretion through crosstalk between cAMP and calcium signaling in mouse inner medullary collecting duct cells. Am J Physiol Cell Physiol 2014;306:C263-C278.

-26 Tsiokas L, Arnould T, Zhu C, Kim E, Walz G, Sukhatme VP: Specific association of the gene product of PKD2 with the TRPC1 channel. Proc Natl Acad Sci USA 1999;96:3934-3939.

27 Bai CX, Giamarchi A, Rodat-Despoix L, Padilla F, Downs T, Tsiokas L, Delmas P: Formation of a new receptor-operated channel by heteromeric assembly of TRPP2 and TRPC1 subunits. EMBO Rep 2008;9:472479.

28 Du J, Ding M, Sours-Brothers S, Graham S, Ma R: Mediation of angiotensin II-induced $\mathrm{Ca} 2+$ signaling by polycystin 2 in glomerular mesangial cells. Am J Physiol Renal Physiol 2008;294:F909-F918.

29 Kottgen M, Buchholz B, Garcia-Gonzalez MA, Kotsis F, Fu X, Doerken M, et al: TRPP2 and TRPV4 form a polymodal sensory channel complex. J Cell Biol 2008;182:437-447.

-30 Li Y, Santoso NG, Yu S, Woodward OM, Qian F, Guggino WB: Polycystin-1 interacts with inositol 1,4,5-trisphosphate receptor to modulate intracellular $\mathrm{Ca}^{2+}$ signaling with implications for polycystic kidney disease. J Biol Chem 2009;284:36431-36441.

- 31 Morel N, Vandenberg G, Ahrabi AK, Caron $\mathrm{N}$, Desjardins F, Balligand JL, et al: PKD1 haploinsufficiency is associated with altered vascular reactivity and abnormal calcium signaling in the mouse aorta. Pflugers Arch 2009; 457:845-856.
32 Mekahli D, Sammels E, Luyten T, Welkenhuyzen $\mathrm{K}$, van den Heuvel LP, Levtchenko EN, et al: Polycystin-1 and polycystin- 2 are both required to amplify inositol-trisphosphate-induced $\mathrm{Ca}^{2+}$ release. Cell Calcium 2012;51:452-458.

33 Jin X, Mohieldin AM, Muntean BS, Green JA, Shah JV, Mykytyn K, Nauli SM: Cilioplasm is a cellular compartment for calcium signaling in response to mechanical and chemical stimuli. Cell Mol Life Sci 2014;71:2165-2178.

34 Muntean BS, Jin X, Williams FE, Nauli SM: Primary cilium regulates CaV1.2 expression through Wnt signaling. J Cell Physiol 2014; 229:1926-1934.

35 Jacobsson L, Lindquist B, Michaelson G, Bjerle P: Fluid turnover in renal cysts. Acta Med Scand 1977;202:327-329.

-36 Mangoo-Karim R, Uchic M, Lechene C, Grantham JJ: Renal epithelial cyst formation and enlargement in vitro: dependence on cAMP. Proc Natl Acad Sci USA 1989;86: 6007-6011.

37 Ye M, Grantham JJ: The secretion of fluid by renal cysts from patients with autosomal dominant polycystic kidney disease. N Engl J Med 1993;329:310-313.

38 Davidow CJ, Maser RL, Rome LA, Calvet JP, Grantham JJ: The cystic fibrosis transmembrane conductance regulator mediates transepithelial fluid secretion by human autosomal dominant polycystic kidney disease epithelium in vitro. Kidney Int 1996;50:208-218.

39 O'Sullivan DA, Torres VE, Gabow PA, Thibodeau SN, King BF, Bergstralh EJ: Cystic fibrosis and the phenotypic expression of autosomal dominant polycystic kidney disease. Am J Kidney Dis 1998;32:976-983.

40 Snyder DS, Tradtrantip L, Yao C, Kurth MJ, Verkman AS: Potent, metabolically stable benzopyrimido-pyrrolo-oxazine-dione (BPO) CFTR inhibitors for polycystic kidney disease. J Med Chem 2011;54:5468-5477.

41 Tradtrantip L, Sonawane ND, Namkung W, Verkman AS: Nanomolar potency pyrimidopyrrolo-quinoxalinedione CFTR inhibitor reduces cyst size in a polycystic kidney disease model. J Med Chem 2009;52:6447-6455.

42 Magenheimer BS, St John PL, Isom KS, Abrahamson DR, De Lisle RC, Wallace DP, et al: Early embryonic renal tubules of wild-type and polycystic kidney disease kidneys respond to CAMP stimulation with cystic fibrosis transmembrane conductance regulator/ $\mathrm{Na}^{+}, \mathrm{K}^{+}, 2 \mathrm{Cl}^{-}$co-transporter-dependent cystic dilation. J Am Soc Nephrol 2006; 17:34243437.

43 Sheppard DN, Welsh MJ: Structure and function of the CFTR chloride channel. Physiol Rev 1999;79(1 suppl):S23-S45.

44 Sullivan LP, Wallace DP, Grantham JJ: Epithelial transport in polycystic kidney disease. Physiol Rev 1998;78:1165-1191.
45 Mangoo-Karim R, Ye M, Wallace DP, Grantham JJ, Sullivan LP: Anion secretion drives fluid secretion by monolayers of cultured human polycystic cells. Am J Physiol 1995;269:F381-F388.

46 Sullivan LP, Wallace DP, Gover T, Welling PA, Yamaguchi T, Maser R, et al: Sulfonylurea-sensitive $\mathrm{K}^{+}$transport is involved in $\mathrm{Cl}^{-}$ secretion and cyst growth by cultured ADPKD cells. J Am Soc Nephrol 2002;13:26192627.

47 Albaqumi M, Srivastava S, Li Z, Zhdnova O, Wulff $\mathrm{H}$, Itani $\mathrm{O}$, et al: $\mathrm{KCa} 3.1$ potassium channels are critical for cAMP-dependent chloride secretion and cyst growth in autosomal-dominant polycystic kidney disease. Kidney Int 2008;74:740-749.

-48 Wallace DP, Rome LA, Sullivan LP, Grantham JJ: cAMP-dependent fluid secretion in rat inner medullary collecting ducts. Am J Physiol Renal Physiol 2001;280:F1019-F1029.

49 Rinschen MM, Schermer B, Benzing T: Vasopressin-2 receptor signaling and autosomal dominant polycystic kidney disease: from bench to bedside and back again. J Am Soc Nephrol 2014;25:1140-1147.

-50 Rieg T, Tang T, Murray F, Schroth J, Insel PA, Fenton RA, et al: Adenylate cyclase 6 determines cAMP formation and aquaporin-2 phosphorylation and trafficking in inner medulla. J Am Soc Nephrol 2010;21:2059-2068.

51 Rieg T, Tang T, Uchida S, Hammond HK, Fenton RA, Vallon V: Adenylyl cyclase 6 enhances NKCC2 expression and mediates vasopressin-induced phosphorylation of NKCC2 and NCC. Am J Pathol 2013;182:96-106.

52 Roos KP, Strait KA, Raphael KL, Blount MA, Kohan DE: Collecting duct-specific knockout of adenylyl cyclase type VI causes a urinary concentration defect in mice. Am J Physiol Renal Physiol 2012;302:F78-F84.

53 Reif GA, Yamaguchi T, Nivens E, Fujiki H, Pinto CS, Wallace DP: Tolvaptan inhibits ERK-dependent cell proliferation, $\mathrm{Cl}^{-}$secretion, and in vitro cyst growth of human ADPKD cells stimulated by vasopressin. Am J Physiol Renal Physiol 2011;301:F1005F1013.

54 Wang CJ, Creed C, Winklhofer FT, Grantham $\mathrm{JJ}$ : Water prescription in autosomal dominant polycystic kidney disease: a pilot study. Clin J Am Soc Nephrol 2011;6:192-197.

55 Torres VE, Chapman AB, Devuyst O, Gansevoort RT, Grantham JJ, Higashihara E, et al: Tolvaptan in patients with autosomal dominant polycystic kidney disease. N Engl J Med 2012;367:2407-2418

56 Wang X, Gattone V 2nd, Harris PC, Torres VE: Effectiveness of vasopressin V2 receptor antagonists OPC-31260 and OPC-41061 on polycystic kidney disease development in the PCK rat. J Am Soc Nephrol 2005;16:846-851.

- 57 Torres VE, Wang X, Qian Q, Somlo S, Harris PC, Gattone VH 2nd: Effective treatment of an orthologous model of autosomal dominant polycystic kidney disease. Nat Med 2004; 10:363-364. 
58 Odgaard E, Praetorius HA, Leipziger J: AVPstimulated nucleotide secretion in perfused mouse medullary thick ascending limb and cortical collecting duct. Am J Physiol Renal Physiol 2009;297:F341-F349.

-59 Jaisser F, Bugeon L, Blot-Chabaud M, Bonvalet JP, Farman N: Effects of AVP and dDAVP on PGE2 synthesis in superfused cortical collecting tubules. Am J Physiol 1989;256:F1044F1050.

60 Wilson PD, Hovater JS, Casey CC, Fortenberry JA, Schwiebert EM: ATP release mechanisms in primary cultures of epithelia derived from the cysts of polycystic kidneys. J Am Soc Nephrol 1999;10:218-229.

61 Buchholz B, Teschemacher B, Schley G, Schillers $\mathrm{H}$, Eckardt KU: Formation of cysts by principal-like MDCK cells depends on the synergy of CAMP- and ATP-mediated fluid secretion. J Mol Med (Berl) 2011;89:251-261.

62 Rajagopal M, Kathpalia PP, Thomas SV, Pao AC: Activation of P2Y1 and P2Y2 receptors induces chloride secretion via calcium-activated chloride channels in kidney inner medullary collecting duct cells. Am J Physiol Renal Physiol 2011;301:F544-F553.

63 Cuffe JE, Bielfeld-Ackermann A, Thomas J, Leipziger J, Korbmacher C: ATP stimulates $\mathrm{Cl}^{-}$secretion and reduces amiloride-sensitive $\mathrm{Na}^{+}$absorption in M-1 mouse cortical collecting duct cells. J Physiol 2000;524:77-90.

64 Kunzelmann K, Mehta A: CFTR: a hub for kinases and crosstalk of cAMP and $\mathrm{Ca}^{2+}$. FEBS J 2013;280:4417-4429.

-65 Elberg G, Elberg D, Lewis TV, Guruswamy S, Chen L, Logan CJ, et al: EP2 receptor mediates PGE2-induced cystogenesis of human renal epithelial cells. Am J Physiol Renal Physiol 2007;293:F1622-F1632.
66 Liu Y, Rajagopal M, Lee K, Battini L, Flores D, Gusella GL, et al: Prostaglandin E(2) mediates proliferation and chloride secretion in ADPKD cystic renal epithelia. Am J Physiol Renal Physiol 2012;303:F1425-F1434.

67 Jansson K, Nguyen AN, Magenheimer BS, Reif GA, Aramadhaka LR, Bello-Reuss E, et al: Endogenous concentrations of ouabain act as a cofactor to stimulate fluid secretion and cyst growth of in vitro ADPKD models via cAMP and EGFR-Src-MEK pathways. Am J Physiol Renal Physiol 2012;303:F982-F990.

68 Belibi FA, Reif G, Wallace DP, Yamaguchi T, Olsen L, Li H, et al: Cyclic AMP promotes growth and secretion in human polycystic kidney epithelial cells. Kidney Int 2004;66: 964-973.

69 Wallace DP, Reif G, Hedge AM, Thrasher JB, Pietrow P: Adrenergic regulation of salt and fluid secretion in human medullary collecting duct cells. Am J Physiol Renal Physiol 2004; 287:F639-F648.

-70 Takiar V, Nishio S, Seo-Mayer P, King JD Jr, Li H, Zhang L, et al: Activating AMP-activated protein kinase (AMPK) slows renal cystogenesis. Proc Natl Acad Sci USA 2011;108: 2462-2467.

71 Zanoli L, Granata A, Lentini P, Rastelli S, Fatuzzo P, Rapisarda F, Castellino P: Sodium-glucose linked transporter-2 inhibitors in chronic kidney disease. ScientificWorldJournal 2015;2015:317507.
72 Wang X, Zhang S, Liu Y, Spichtig D, Kapoor S, Koepsell H, et al: Targeting of sodium-glucose cotransporters with phlorizin inhibits polycystic kidney disease progression in Han:SPRD rats. Kidney Int 2013;84:962-968.

73 Kapoor S, Rodriguez D, Riwanto M, Edenhofer I, Segerer S, Mitchell K, Wuthrich RP Effect of sodium-glucose cotransport inhibition on polycystic kidney disease progression in PCK rats. PLoS One 2015;10:e0125603.

74 Nitta K, Nagano N, Tsuchiya K: Fibroblast growth factor 23/klotho axis in chronic kidney disease. Nephron Clin Pract 2014;128:110.

75 Spichtig D, Zhang H, Mohebbi N, Pavik I, Petzold K, Stange G, et al: Renal expression of FGF23 and peripheral resistance to elevated FGF23 in rodent models of polycystic kidney disease. Kidney Int 2014;85:1340-1350.

-76 Pavik I, Jaeger P, Ebner L, Poster D, Krauer F, Kistler AD, et al: Soluble klotho and autosomal dominant polycystic kidney disease. Clin J Am Soc Nephrol 2012;7:248-257.

77 Devuyst O: The expression of water channels AQP1 and AQP2 in a large series of ADPKD kidneys. Nephron 1998;78:116-117.

78 Bachinsky DR, Sabolic I, Emmanouel DS, Jefferson DM, Carone FA, Brown D, Perrone RD: Water channel expression in human ADPKD kidneys. Am J Physiol 1995;268: F398.

79 Noda Y, Sohara E, Ohta E, Sasaki S: Aquaporins in kidney pathophysiology. Nat Rev Nephrol 2010;6:168-178.

-80 Wang W, Li F, Sun Y, Lei L, Zhou H, Lei T, et al: Aquaporin-1 retards renal cyst development in polycystic kidney disease by inhibition of Wnt signaling. FASEB J 2015;29:15511563. 